\title{
Physical Modeling and Numerical Simulation of the Seismic Responses of Metro Tunnel near Active Ground Fissures
}

\author{
Nina Liu $\mathbb{D}$, ${ }^{1,2,3}$ Quanzhong Lu $\left(\mathbb{D},{ }^{2,3}\right.$ Jun Li $\left(\mathbb{D},{ }^{2}\right.$ Jianbing Peng $\mathbb{D}^{2,3}$ Wen Fan $\mathbb{D}^{2,3}$ \\ and Weiliang Liu $\mathbb{C}^{4}$ \\ ${ }^{1}$ Key Laboratory of Mine Geological Hazards Mechanism and Control, Chang'an University, Xi'an 710054, China \\ ${ }^{2}$ School of Geological Engineering and Geomatics, Chang'an University, Xi'an 710054, China \\ ${ }^{3}$ Key Laboratory of Western China's Mineral Resource and Geological Engineering Ministry of Education, Chang'an University, \\ Xi'an 710054, China \\ ${ }^{4}$ School of Marine Sciences, Sun Yat-sen University, Guangzhou 510275, China \\ Correspondence should be addressed to Nina Liu; dcdgx16@chd.edu.cn and Quanzhong Lu; dcdgx14@chd.edu.cn
}

Received 7 April 2019; Revised 4 July 2019; Accepted 5 October 2019; Published 30 October 2019

Academic Editor: Christos Volos

Copyright ( 2019 Nina Liu et al. This is an open access article distributed under the Creative Commons Attribution License, which permits unrestricted use, distribution, and reproduction in any medium, provided the original work is properly cited.

\begin{abstract}
Ground fissures pose serious hazards to underground, as well as aboveground, structures. In underground railways, which are near ground fissures, the potential for disasters is even higher since tunnels face threats from fissure activities. To determine the interaction between a tunnel and ground fissure in the event of an earthquake, field surveys and data analysis were applied to study the activity and damage caused by the fissure. Shaking table tests and a numerical simulation model were used to understand the dynamic response of the fissure site and tunnel. The fissure site had a clear hanging wall effect, where the acceleration amplification was larger in the hanging wall than that in the footwall both on the surface and at the middle of the fissure site. The zone of influence was also wider in the hanging wall. The acceleration magnification factor increased with the burial depth and peak acceleration of the input earthquake. The peak ground acceleration (PGA) decreased with the burial depth on both sides of the fissure. The greatest PGA coefficient was obtained at the surface of the site. The vertical soil pressure was influenced by the metro tunnel and fissure. The vertical soil pressure was larger in the hanging wall, especially in the zone near the fissure, but was less near the tunnel. The horizontal soil pressure above the tunnel was less than that near the fissure. The results of this study are essential for the safe design of underground railway systems.
\end{abstract}

\section{Introduction}

Ground fissures are a global geological hazard and have been studied since historical times. Charles Lyell described the different types of fissures and their origins in Elements of Geology in the $19^{\text {th }}$ century. In the USA, the first ground fissure was discovered in the Goose Creek oil field of Texas in 1918, with a second fissure found in the Picaho Basin of Arizona in 1927. Since then, ground fissures have been found in Arizona, California, Texas, Nevada, New Mexico, and other states in the USA [1]. Ground fissures have also been observed in other countries, such as Mexico; Bulgaria; Chamoli, India; Iran; Japan; and China [2-7].
Monitoring approaches using the integrated global positional system (GPS) and interferometric synthetic aperture radar (InSAR) have discovered the activity and development trends of these ground fissures [8]. The formation paradigm of ground fissures has been studied in the past decades. The tectonic dynamics, hydrodynamics, and disaster mechanisms have a close relationship with a fissure's origin and activity [9]. Tectonic forces that are driven by crustal stress control the formation of ground fissures. Hydrodynamic forces both intensify and reactivate ground fissure activity. Research in the Fenwei Basin has revealed that the ground fissure has clear syngenetic fault features. The main ground fissures are the outcrops of an underlying structural rupture, whose location and activity are usually controlled by 
underlying faults. Moreover, their activity is usually dominated by vertical displacement, i.e., twist and stretch have less influence on activity $[9,10]$.

Thus far, more than 6,000 ground fissures have been found in China [9]. In the Fenwei Basin, there are 195 fissures, mostly distributed in Xi'an, Xianyang, and Weinan. The first fissure in Xi'an was discovered on the Northwest University campus in 1959. Since then, 14 ground fissures, with a total length of $160 \mathrm{~km}$, have been found in Xi'an. The coverage area is approximately $250 \mathrm{~km}^{2}$. These fissures, termed as $f_{1}, \ldots, f_{14}$ from north to south, are located in the Fenwei Basin. They are developed along the Chang'anLingtong active fault and the edge of groundwater depression cones $[8,9]$.

Xi'an is the biggest city in Northwestern China and is one of China's ancient capitals. Ground fissures have caused serious damage in Xi'an City. In the affected areas, roads have been cutoff, pipes broken, farmlands destroyed, and buildings damaged, including buildings of historical significance. For example, the Bell Tower and Dayan Pagoda Tower, which are landmarks with thousands of years of history, have been significantly influenced by ground fissures; the former has settled $395 \mathrm{~mm}$ while the latter is tilting to the northwest by $1,100 \mathrm{~mm}$. From a financial perspective, the damage caused by ground fissures has led to losses that amount to more than 10 billion Yuan in Xi'an $[10,11]$.

The development of Xi'an is limited by these ground fissures. The city has a plan to develop 23 underground railway lines but all intersect the 14 ground fissures, threatening the safety of the underground railways. Although several measures have been taken to avoid and mitigate the negative impacts of ground fissures while designing the railway lines, research is still essential to ensure the safety of the metro in the fissure areas.

To identify the deformation and mechanics of metro tunnels influenced by ground fissures, large-scale physical modeling and numerical simulations have been used to model the underground railways that cross the ground fissure areas. The metro tunnels and ground fissures are in close proximity to the railway line, i.e., this short distance will influence the safety of the tunnel, especially during earthquakes. This study was conducted with the objective of determining the influence that ground fissures have on various factors that affect the design of railway tunnels. The results of this study may help in the effective implementation of ground fissure mitigation technologies for underground railways and other buildings in fissure-prone areas.

\section{The $f_{7}$ Ground Fissure}

2.1. Activity of the $f_{7}$ Ground Fissure. The $f_{7}$ ground fissure is one of the 14 fissures with strong activity in Xi'an [7]. Beginning from the North ridge in the southwest of the city, the $f_{7}$ fissure crosses Xiaozhai, Xiying Road, and ends at the Fangzhi District in the northeast. With a total length of $28 \mathrm{~km}$ and a visible portion length of $13 \mathrm{~km}$, the $f_{7}$ ground fissure is the longest of the 14 ground fissures. Figure 1 shows the $f_{7}$ ground fissure.
GPS and InSAR monitoring methods have been applied to identify the distribution and activity of the $f_{7}$ ground fissure. Based on dating analyses, the $f_{7}$ ground fissure has been reactivated three times due to water pumping in the past 50 years [10]. Figure 2 depicts the average annual displacement of the $f_{7}$ fissure since 1960 . There are three periods when serious displacement occurred based on the recorded data. The first period was from 1960 to 1989, with an average displacement of $3.2 \mathrm{~mm} /$ year. The $f_{7}$ fissure was first observed during this period. The activity increased sharply to $35.00 \mathrm{~mm} /$ year in the second period from 1990 to 1996. Groundwater removal was the primary reason for large displacement during this period. In the third period, from 1997 to 2005, the average activity decreased to $15.00 \mathrm{~mm} /$ year with the ban of groundwater removal [11]. The largest displacement, at $50 \mathrm{~mm} /$ year, occurred at the end of the 1980s. Based on the average displacement, the accumulated total displacement of the ground fissure during the first period was $97.00 \mathrm{~mm}$, which increased to $245.0 \mathrm{~mm}$ in the second period, and, then, decreased to $135.00 \mathrm{~mm}$ during the third period. The average annual (Figure 2) and cumulative displacement indicate that hydrodynamic forces intensified and reactivated the activity of the $f_{7}$ fissure [10].

There are six monitoring stations along the $f_{7}$ fissure, located at Xiwan Road (M1), Jixiangcun (M2), Xiaozhai (M3), Cuihua Road (M4), Houcui (M5), and Xiying Road (M6) from west to east (Figure 1(a)). Figure 3 depicts the data recorded for the accumulated displacement from 1989 to 2007. The maximum accumulated displacement at M1 was $20.10 \mathrm{~mm}, 24.51 \mathrm{~mm}$ at M4, $417.43 \mathrm{~mm}$ at M5, and $309.83 \mathrm{~mm}$ at M6 during the period from 1989 to 2007. The two monitoring stations (M5 and M6) located at the southeastern zone of the fissure recorded higher displacements than the other four stations. The M5 and M6 monitoring stations are located at the edge of groundwater depression cones. The displacement has a close relationship with the underground water level in the area [12].

Based on an analysis of the monitoring data from the M6 station from 2001 to 2007 [7, 10-12], we observed that the displacement consists of vertical displacement, stretch, and twist. The fissure stretches by an average of $0.436 \mathrm{~mm} /$ year. The twist is mainly directed to the left with an average value of $1.38 \mathrm{~mm} /$ year. The vertical displacement recorded at station M6 is mainly due to hanging wall subsidence, with an average settling of $2.032 \mathrm{~mm} /$ year. The ratio among the three types of displacement was as follows: vertical displacement: twist : stretch $=1: 0.68: 0.22$. The vertical displacement was determined to be the key factor that affects the displacement of the fissure, i.e., vertical displacement usually dominated $f_{7}$ ground fissure movement.

2.2. Relationship between Earthquakes and the $f_{7}$ Ground Fissure. In recent years, Xi' an City and adjacent areas have periodically experienced earthquakes. For example, an earthquake, with an intensity of $3.0 \mathrm{Ms}$ occurred in the Yanliang District in the northeastern section of Xi'an on June 13, 2018. Another earthquake (5.3 Ms) occurred in Ningqiang Town on September 13, 2018. There is a close 


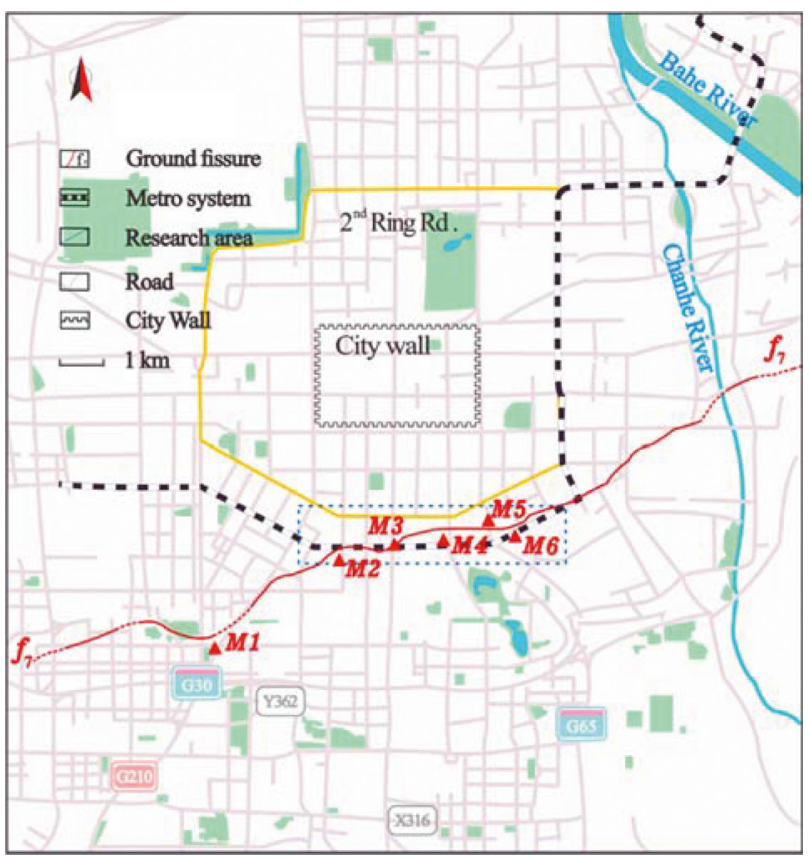

(a)

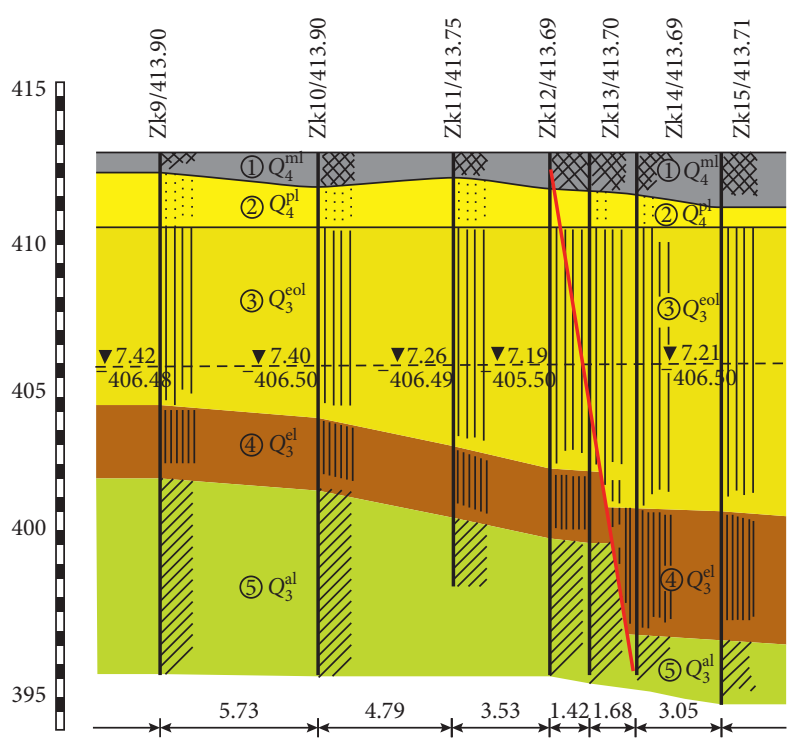

(b)

Figure 1: The study area in Xi'an city. (a) The metro tunnel and $f_{7}$ ground fissure. (b) The geological profile of the ground fissure (unit: $\mathrm{m}$ ).

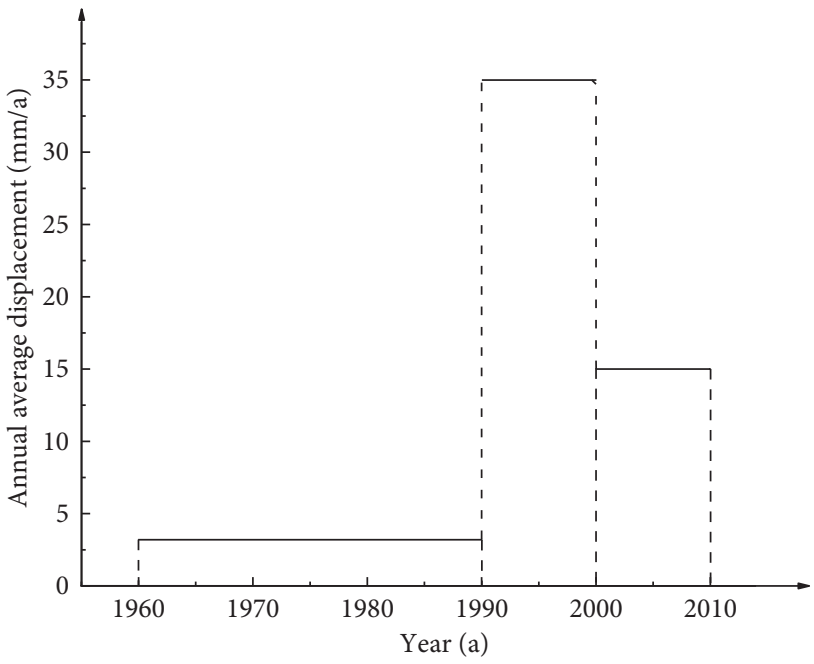

Figure 2: The displacement of the $f_{7}$ ground fissure from 1960 to 2010.

relationship between ground fissure activity and earthquake occurrence. For example, the M6 monitoring station recorded sudden settling during the Wenchuan earthquake in 2008 [12]. Land subsidence sharply increased at the time of the earthquake, which indicates that earthquakes definitely influence the activity of the $f_{7}$ fissure. Increased ground fissure activity caused by earthquakes can usually be divided into three phases. The first phase is a sudden settling that corresponds to the occurrence of the earthquake. The second phase is characterized by moderate settling that usually lasts for several days after the earthquake. The third phase is barely noticeable and is comprised of continued

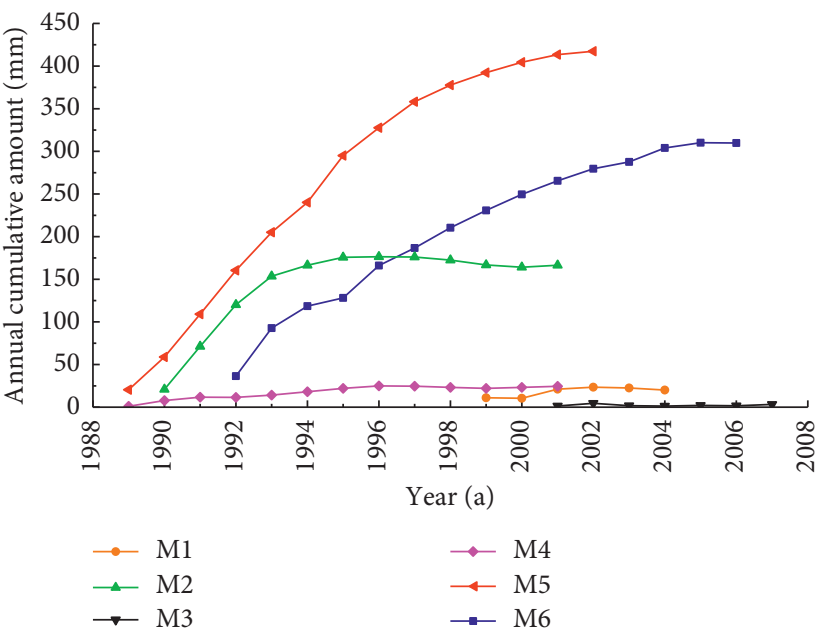

FIgURE 3: The annual cumulative displacement of the $f_{7}$ ground fissure from 1988 to 2008 .

motion that typically lasts for months or years after the earthquake. The earthquake can reactivate pre-existing ground fissures, where associated land subsidence caused by an earthquake can also lead to the development of new ground fissures [11].

2.3. Damage Caused by the $f_{7}$ Ground Fissure. Underground structures, such as water and natural gas pipelines, have been broken more than 45 times due to ground fissure activity since 1976. An investigation revealed that more than 10 pipelines were broken by ground fissure activity in 2003 [10]. Since the soil in Xi'an city is 
predominantly loess, water leakage from the broken pipes causes the soil to soak and collapse, which leads to secondary damage, such as serious uneven ground settling and the deformation of buildings and roads [9].

Figure 4(a) shows the deformation of a road near the M4 monitoring station caused by $f_{7}$ ground fissure activity. The central axis of the road lifted resulting in the subsidence of the road shoulder, with a vertical displacement of approximately $200 \mathrm{~mm}$. Figure 4(b) illustrates wall damage caused by the $f_{7}$ ground fissure near the M6 monitoring station. One side of the wall lifted while the other side subsided. Similar examples can be observed throughout the city.

\section{Experimental Setup and Construction Site}

3.1. Physical Description of the Area Used for the Model Prototype. The $3^{\text {rd }}$ line of the Xi'an metro runs nearly parallel to the ground fissures at several sites, as shown in Figure 1(a). Near Xiaozhai Station, the distance between the fissure and tunnel is only approximately $20 \mathrm{~m}$. Ground fissure activity easily influences the metro tunnel. Thus, the construction site at Xiaozhai Station, the associated metro tunnel, and the $f_{7}$ ground fissure were the prototypes in this study.

Figure 1(b) shows the strata profile of the study area based on a field survey. The dills, as Zk9 to Zk15, were applied to obtain detailed strata features. Four strata exist between the ground surface and bottom of the subway tunnel: postglacial artificial earth fill $\left(Q_{4}^{\mathrm{ml}}\right)$, upper Pleistocene aeolian loess $\left(Q_{3}^{\mathrm{eol}}\right)$, residual palaeosols $\left(Q_{3}^{\mathrm{el}}\right)$, and middle Pleistocene alluvial silty clay $\left(Q_{2}^{\mathrm{al}}\right)$. Based on the strata profile, the hanging wall and footwall have different depths for each stratum along the ground fissure, i.e., each layer of the hanging wall is lower than that of the footwall. This is especially the case at the bottom of the middle Pleistocene alluvial silty clay layer, i.e., a difference of up to $4.0 \mathrm{~m}$. The landscape of this area is flat, with a ground elevation of 409.46-441.43 m. The geomorphic unit consists of a loess ridge and depression. The metro tunnel occurs between a depth of approximately $10-15 \mathrm{~m}$ and has a horseshoe shape, with a height of $9.55 \mathrm{~m}$.

3.2. Model Design. A shaking table test was used to simulate earthquakes for the model of the prototype site, including the fissure and metro tunnel. The shaking table is a useful piece of equipment in earthquake research, which can apply dynamic earthquake loads to the model developed on the table. The shaking table was applied to study the uniqueness and complexity of the site with the metro tunnel and parallel ground fissure. The shaking table was made by MTS, with electrically controlled power. The functioning mechanism of the metro tunnel is essential for safe designs. The dynamic response of the tunnel with respect to acceleration and soil pressure were monitored, compared, and analyzed.

As shown in Figure 5(a), the size of the shaking table was $4 \mathrm{~m} \times 4 \mathrm{~m}$, with a maximum capacity of $30 \mathrm{t}$ and a maximum horizontal acceleration of $\pm 1.5 \mathrm{~g}$. The dimensions of the laminar shear model container were as follows: $3.0 \mathrm{~m}$ (length) $\times 1.5 \mathrm{~m}$ (width) $\times 1.2 \mathrm{~m}$ (height). The container was designed with three types of boundaries to reduce the boundary effect. The sliding boundary was parallel to the shaking direction, the flexible boundary was perpendicular to the shaking direction, and the friction boundary was at bottom of the model box (Figures 5(a) and 5(b)).

The geometric similarity ratio was set to $1 / 30$, based on the capabilities of the shaking table. The key characteristics used to create the dynamic model design included the geometric similarity constant, the density similarity constant, and the modulus of elasticity; based on the geometric similarity ratio, these were 30 in total. Other physical characteristics were determined via Buckingham's $\pi$ theorem and dimensional analysis [13-17]. The soil used in the model was obtained from the construction site. The soil was filled layer by layer into the container following the layers of the strata profile. We ensured that the water content and soil density were identical to these parameters at the original site. The soil unit weight was $18.6 \mathrm{kN} \cdot \mathrm{m}^{-3}$. The filled material in the fissure was fine sand according to the field survey. The width of the model fissure was $25 \mathrm{~mm}$, with a tilt angle of $80^{\circ}$. The model tunnel was also simulated in accordance with the similarity relationship. Based on the orthogonal method of the material, the proportions of the material used to construct the tunnel were plaster: water : barite powder $=1: 1$ : 3.95. The rebar of the tunnel was simulated using aluminum wire mesh based on the equal ratio strength of the rebar between the model and prototype tunnel. The thickness of the model tunnel was $18 \mathrm{~mm}$, in accordance with the thickness of the prototype tunnel of $550 \mathrm{~mm}$. The overall dimensions of the prototype tunnel were $9,550 \mathrm{~mm}$ in height and $9,400 \mathrm{~mm}$ in width with a horseshoe-shaped profile. Other characteristics of the tunnel were as follows: Young's modulus $(E)$ of $3,000.0 \mathrm{MPa}$, compressive strength of $4.97 \mathrm{MPa}$, and density of $23.5 \mathrm{kN} \cdot \mathrm{m}^{-3}$ [16]. Figure $5(\mathrm{c})$ shows an image of the model tunnel.

3.3. Data Acquisition System. During shaking table tests, ensuring that the earthquake simulations are accurate is important to obtain test results that are reliable. The synthetic Xi'an earthquake wave was selected for the model experiment, with characteristics matching the geological characteristics of the study area. In addition, two other known earthquake waves, i.e., the El Centro earthquake and Kobe earthquake waves, were applied. The El Centro wave was recorded in Empire Valley, USA in 1940 and the Kobe earthquake wave was recorded in Japan in 1995. The El Centro and Kobe earthquake waves were adjusted in accordance with the geological characteristics of Xi'an. The three earthquake waves were loaded onto the shaking table via the control system with increasing peak accelerations of $0.1,0.15$, and $0.3 \mathrm{~g}$. A white noise with a peak acceleration of $0.03 \mathrm{~g}$ was also loaded to confirm the natural vibration frequency of the model box at each event before changing the stage of the earthquake waves.

Acceleration transducers and miniature soil pressure sensors were used during the test to acquire data from the soil and tunnel. Figure 5(d) shows the location of the 


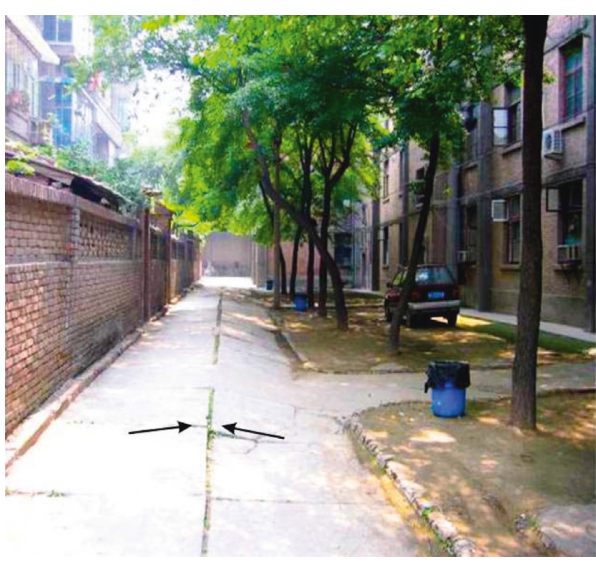

(a)

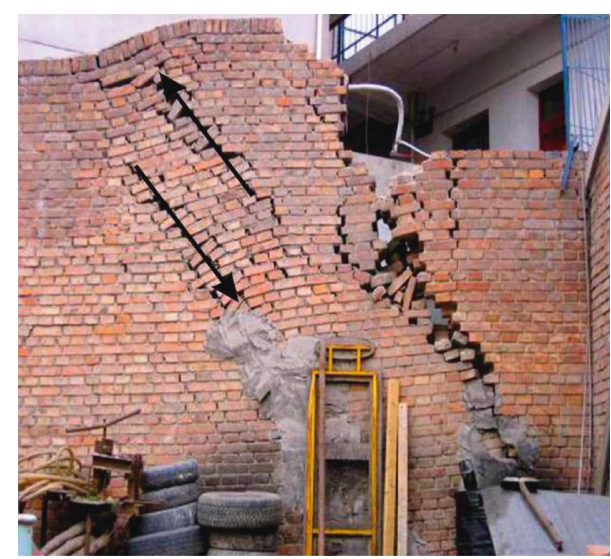

(b)

FIgURe 4: Examples of the damage caused by the $f_{7}$ ground fissure. (a) Damage near monitoring station M4. (b) Damage near monitoring station M6.

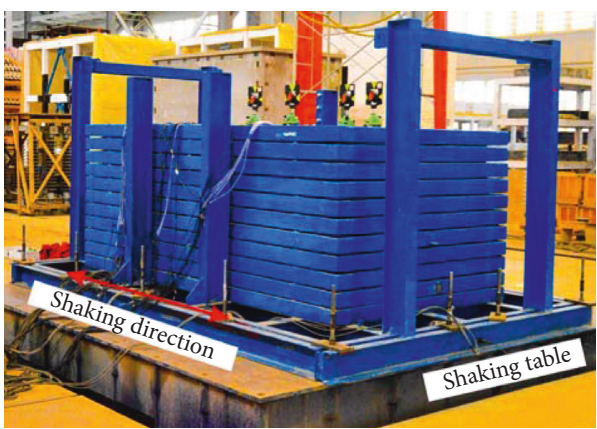

(a)

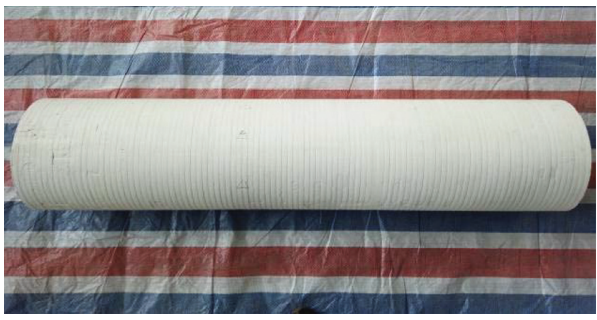

(c)

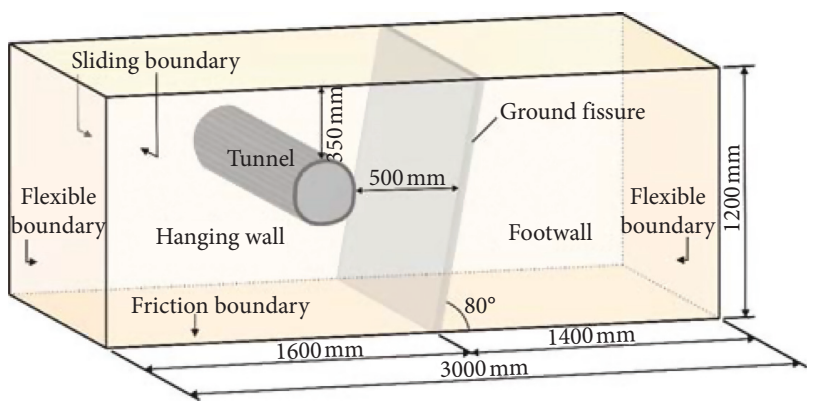

(b)

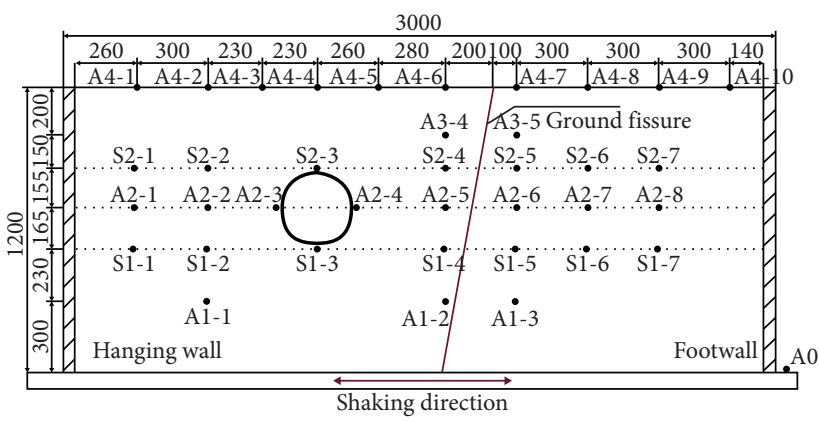

(d)

Figure 5: Model design. (a) The model box and shaking table. (b) A sketch of the model box. (c) The model tunnel. (d) A diagram of the model test (unit: $\mathrm{mm}$ ).

equipment and sensors. In Figure 5(d), "A" denotes an acceleration transducer and " $\mathrm{S}$ " represents a soil pressure sensor. The total number of acceleration transducers and soil pressure sensors were 24 and 14, respectively.

3.4. Numerical Analysis Model. The Fast Lagrangian Analysis of Continua in $3 \mathrm{D}\left(\mathrm{FLAC}^{3 \mathrm{D}}\right)$ was used for numerical simulations of the model. The developed model was based on the study area where the $f_{7}$ fissure is near the tunnel for the $3^{\text {rd }}$ line of the Xi'an Metro. The size of the simulation model was $3.0 \mathrm{~m}$ in length, with a depth of $1.2 \mathrm{~m}$. The soil layers applied in the numerical model were identical to those used at the prototype construction site. The synthetic Xi'an earthquake wave was applied in the numerical simulation model, with the selection of peak accelerations for this study that corresponded to the shaking table test at $0.1,0.15$, and $0.3 \mathrm{~g}$.

Numerical simulations are essential in dynamic experiments. The shaking table test is expensive and test preparations require a significant amount of time. On the contrary, the numerical simulation model may provide 
useful data with less time and cost restraints. Moreover, it is an important method to compare and analyze the data obtained from model tests.

In the numerical simulation model, the finite element method of plan strain was used to reduce the calculation time. The viscous boundary was placed at the bottom of the model, and a free-field boundary was designed on both sides of the model. The boundaries were applied to reduce seismic wave reflection. The constitutive soil model was based on the Mohr-Coulomb yield criterion. The fissure was simulated via thin layer elements. Figure 6 shows the numerical simulation model prepared using the FLAC ${ }^{3 \mathrm{D}}$ software.

\section{Results of Model Tests and Numerical Simulations}

4.1. Acceleration Amplification. We considered the peak acceleration recorded by the acceleration transducer, A0, as the basic peak acceleration. Here, A0 was fixed onto the surface of the shaking table. The ratio of the peak acceleration from each transducer to the basic peak acceleration is referred to as the acceleration amplification factor. Figure 7 depicts the acceleration amplification on the surface of the site when loading the synthetic Xi'an earthquake wave, as well as the Kobe and El Centro earthquake waves. Figures $7(\mathrm{a})-7(\mathrm{c})$ show that the earthquake waves were amplified onto the surface of the shaking table, particularly onto the surface of the hanging wall. For the majority of the monitoring points, the amplification coefficients were larger than 1.0. The largest amplification factor was obtained from the point next to the fissure on the hanging wall. The amplification factor curves decreased towards both sides on the hanging wall and footwall. In the hanging wall, the decrease in the amplification factor became gentler at a distance of $1.0 \mathrm{~m}$ from the fissure while, in the footwall, this phenomenon was observed at a distance of $0.5 \mathrm{~m}$ from the fissure. The amplification factors were larger for the hanging wall than those for the symmetric component of the footwall. The width of the influenced zone, as well as the amplification factor, was larger in the hanging wall. This phenomenon is known as the "hanging wall effect" in normal faults. In other words, the hanging wall amplifies the earthquake more than the footwall in a normal fault. Based on the results shown in Figure 7, we observe the same feature in the ground fissure area. Thus, the ground fissure site also experiences the hanging wall effect.

Figure 8 depicts the acceleration amplification coefficient at a depth of $505 \mathrm{~mm}$. According to Figure 5(d), a burial depth of $505 \mathrm{~mm}$ corresponds to the tunnel arch. The acceleration transducers were A2-1, A2-2, and up to A2-8 (Figure 5(d)). The ratio of the peak acceleration, from the transducers, to the basic peak acceleration is known as the acceleration amplification coefficient. Except for different peak accelerations of $0.1,0.15$, and $0.3 \mathrm{~g}$, the amplification curves had similar characteristics. Figure 8 shows that the amplification coefficient was largest at a distance of $-0.5 \mathrm{~m}$ from the fissure, i.e., the point located next to the right arch tunnel, where the amplification factor decreased towards both sides. The amplification factor decreased with a corresponding increase in the peak acceleration, whose influence was more prominent in response to the synthetic Xi'an earthquake wave. The main reason for this result was that the low-frequency portion of the synthetic Xi'an earthquake wave was larger than that of the two other earthquake waves. The ground fissure site also amplified the acceleration in the hanging wall during the earthquake at a depth of $505 \mathrm{~mm}$. The hanging wall effect was observed at a depth of $505 \mathrm{~mm}$, as well as at the surface of the site.

Figure 9 indicates the relationship between the acceleration amplification factor and depth along the hanging wall. The acceleration amplification coefficient is the ratio of the peak acceleration to the peak acceleration at the basic acceleration transducer A1-1 (i.e., the transducer at the bottom of the model). Figure 9 illustrates that the amplification coefficient decreased with depth in the hanging wall for all three types of earthquake waves, with peak accelerations of $0.1,0.15$, and $0.3 \mathrm{~g}$. When the peak acceleration of the earthquake was $0.1 \mathrm{~g}$ (Figure 9(a)), the amplification coefficient of the El Centro wave was the largest. This shows that the amplification coefficient depends on the frequency and spectrum characteristics of the earthquake since the El Centro wave had a higher frequency than the other waves. The amplification was consistent with the three wave spectra bandwidth.

When the peak acceleration of the earthquake was 0.15 and $0.3 \mathrm{~g}$ (Figures 9(b) and 9(c), respectively), the amplification coefficient of acceleration was altered. The acceleration amplification coefficients of the synthetic Xi'an wave were the largest, followed by that of the Kobe and El Centro waves. This difference is related to the nonlinearity of the soil when exposed to significant deformation. The magnification factor of the acceleration decreased with the burial depth and the range of the acceleration magnification factor decreased continuously with an increasing peak earthquake acceleration. The difference in acceleration response gradually decreased.

4.2. Rules of Peak Ground Acceleration (PGA). Figure 10 indicates the peak ground acceleration (PGA) coefficient curves at the surface and at a burial depth of $505 \mathrm{~mm}$ based on the numerical simulations and shaking table experiments. Figure 10(a) indicates that the PGA curves obtained via both approaches are similar. The area from -0.48 to $0.4 \mathrm{~m}$ near the fissure had the largest PGA coefficient. The area shown in Figure 10(a) includes $14 \mathrm{~m}$ of the hanging wall and $12 \mathrm{~m}$ of the footwall, which corresponds to the construction zone at the prototype site for the model as the major influence area. The PGA data from the numerical simulation were slightly larger than those obtained from the shaking table test, but the difference was not obvious. While the area above the tunnel had little effect on the PGA coefficient, the tunnel structure did affect the propagation of seismic waves in the soil, which caused scattering and wave reflection in the structure of the tunnel and soil. This reduced the acceleration response above the tunnel compared to the response in other areas surrounding the tunnel and fissure. 


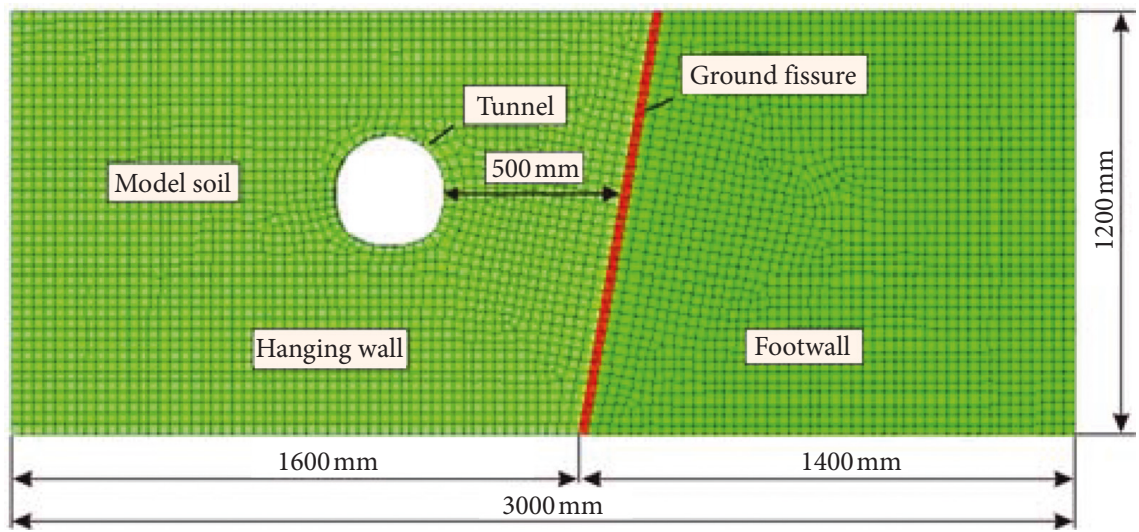

FIgURE 6: The numerical simulation model.
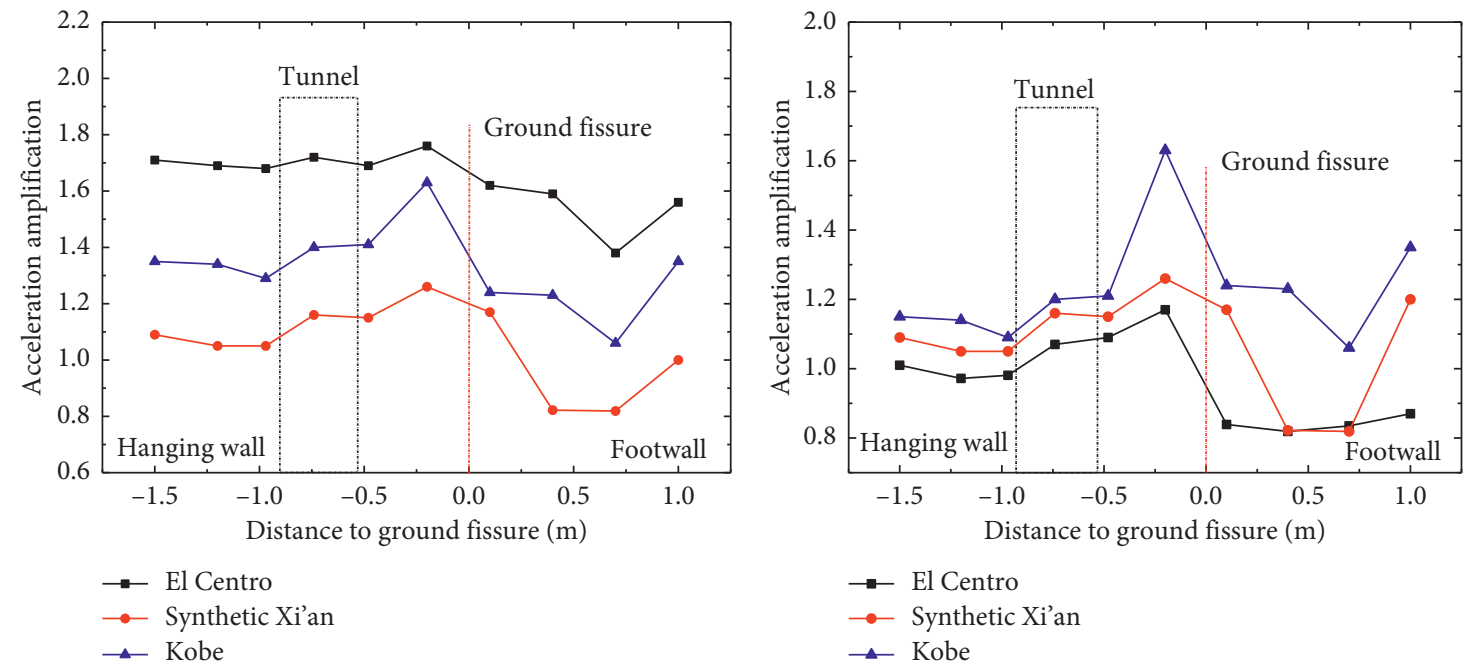

(a)

(b)

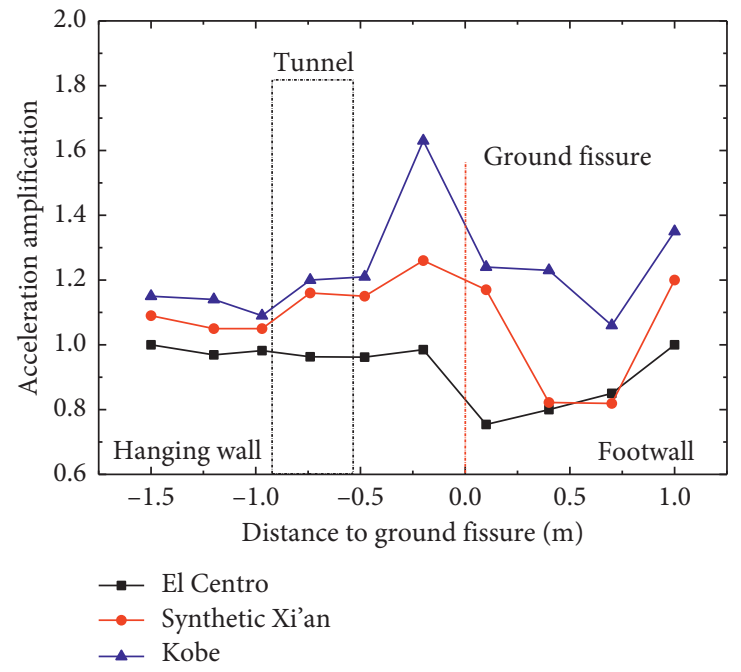

(c)

Figure 7: The acceleration amplification at the surface. (a) $A=0.1$ g. (b) $A=0.15 \mathrm{~g}$. (c) $A=0.3 \mathrm{~g}$.

As shown in Figure 10(b), the results from the shaking table test and numerical simulation model are in good agreement. The curves have a clear crest, where the
PGA magnification factor in the middle of the right arch, which is near the ground fissure, is the largest and gradually decreased on both sides. The acceleration 


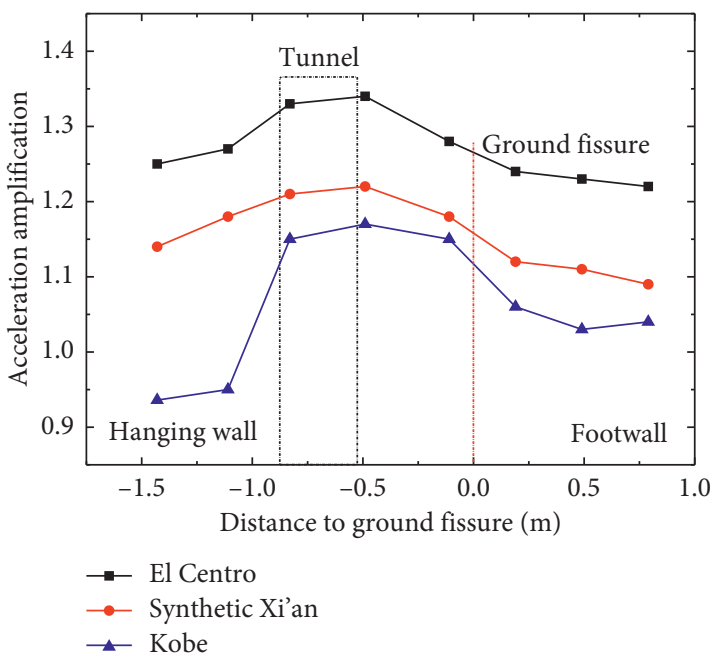

(a)

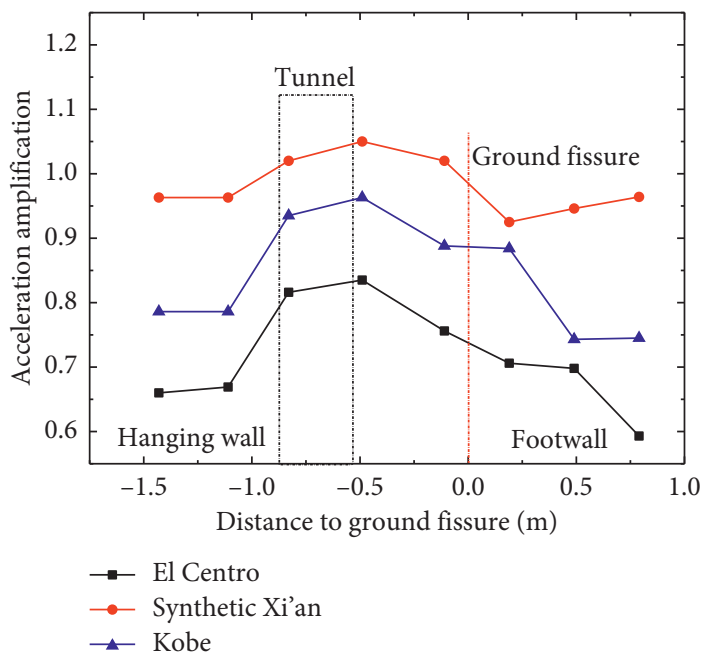

(b)

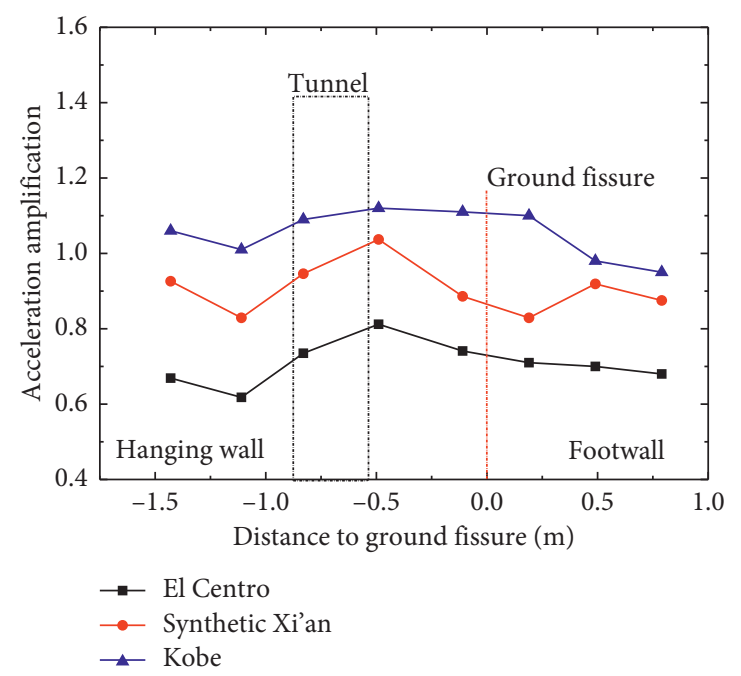

(c)

Figure 8: The acceleration amplification at a depth of $505 \mathrm{~mm}$. (a) $A=0.1 \mathrm{~g}$. (b) $A=0.15 \mathrm{~g}$. (c) $A=0.3 \mathrm{~g}$.

response of the hanging wall and footwall near the ground fissure were different, with a hanging wall acceleration response that was larger than that of the footwall.

4.3. Relationship between $P G A$ and Depth. Figure 11 shows that the PGA coefficients changed with depth in the hanging wall and footwall. Data from the shaking table tests were recorded from the acceleration transducers closest to the fissure on each side: A1-1, A2-5, A3-4, and A4-6 in the hanging wall and A1-3, A2-6, A3-5, and A4-7 in the footwall. The data were obtained from the same positions used in the numerical model. The curves were similar in the numerical simulations and shaking table tests, both in the hanging wall and the footwall. The curves indicated that the PGA decreased with depth on both sides of the fissure. The largest PGA coefficient was 2.2 , which occurred at the surface of the hanging wall site.
4.4. Soil Pressure Increment. Figure 12 depicts the increments in the soil pressure after the synthetic Xi'an earthquake with peak accelerations of $0.1,0.15$, and 0.3 . Figure 12 (a) shows the vertical soil pressure increments recorded by the miniature soil pressure sensors located at a burial depth of $670 \mathrm{~mm}$. The depth is approximately the same as the bottom of the model tunnel, as shown in Figure 5(d). There were a total of seven soil pressure sensors (S1-1 to S1-7), with four sensors in the hanging wall and three sensors in the footwall.

The vertical soil pressure shows incrementation with the earthquake intensity in the hanging wall and footwall. Increments in the vertical soil pressure were the smallest at the bottom and left side of the tunnel while they were larger in the footwall, as shown in Figure 12(a). As a result, due to settling of the hanging wall, as well as the resistance of the tunnel itself to the subsidence in the soil above it, a void space appeared under the tunnel. The vertical soil pressures changed little near the tunnel in the hanging wall. In the footwall, the vertical soil pressures were larger, primarily due to the earthquake. 


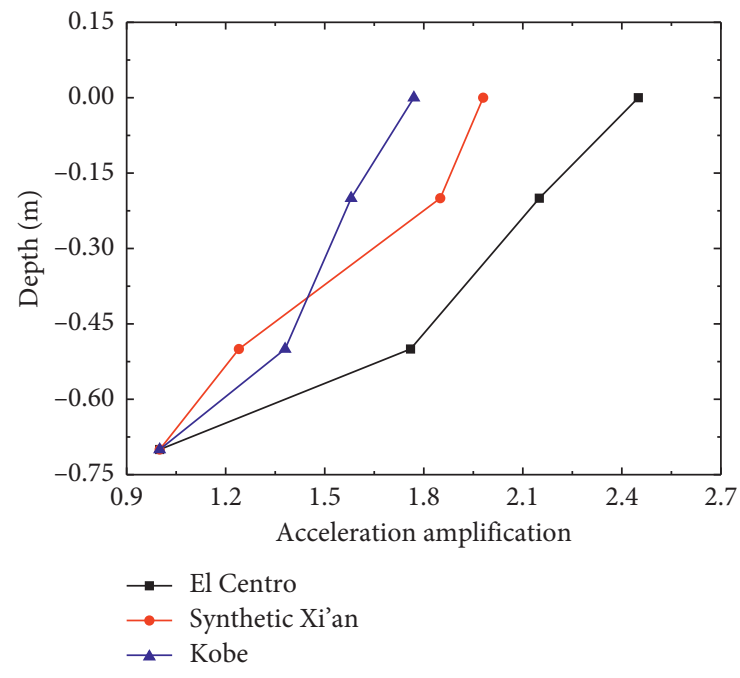

(a)

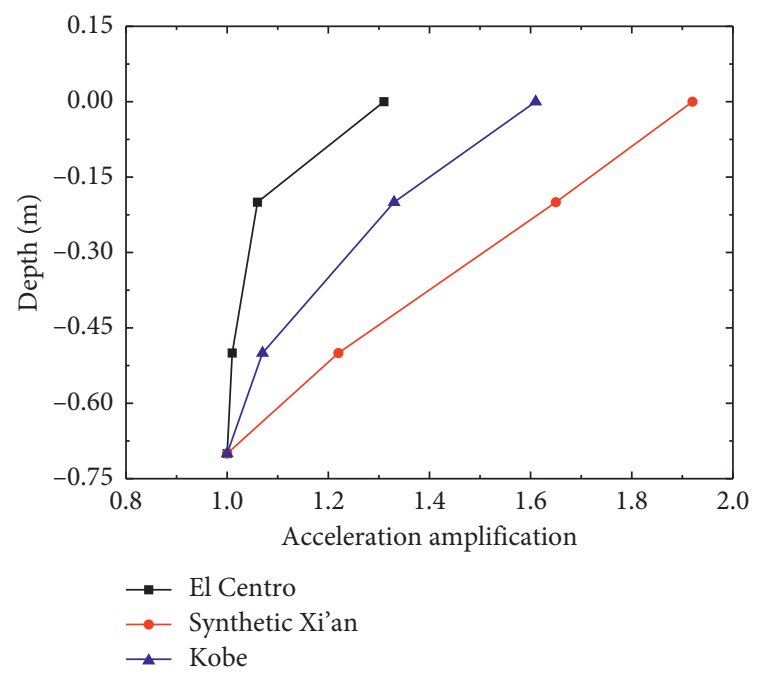

(b)
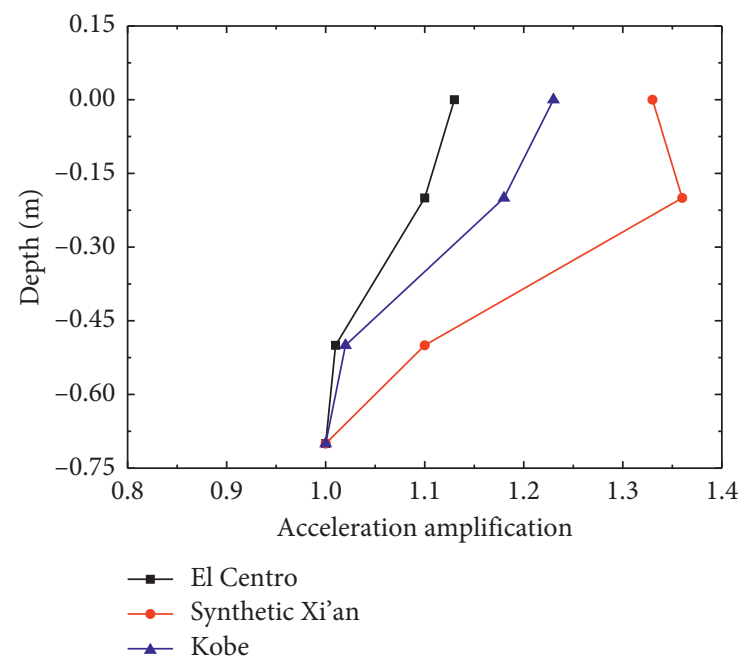

(c)

FIgURe 9: The relationship between the acceleration amplification and depth. (a) $A=0.1$ g. (b) $A=0.15$ g. (c) $A=0.3 \mathrm{~g}$.

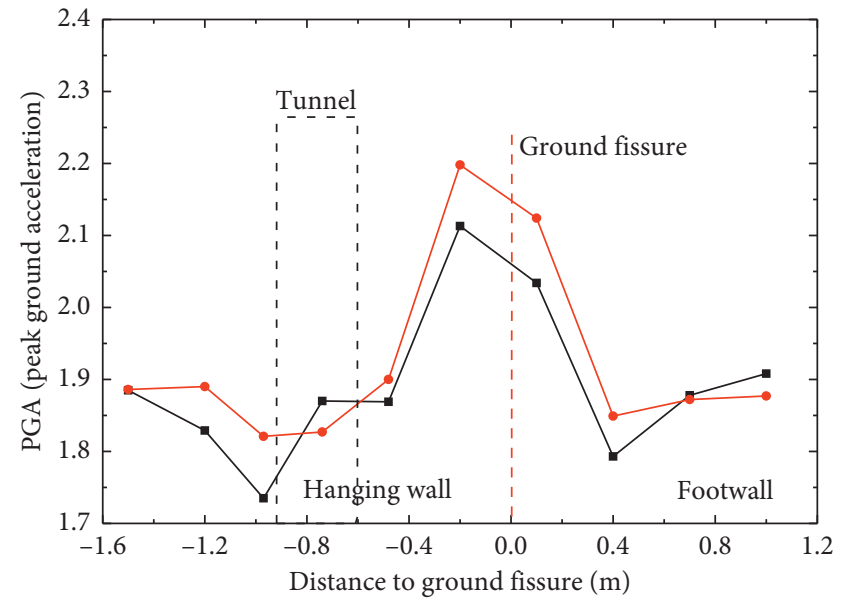

$\rightarrow$ Shaking table

$\rightarrow$ Simulation

(a)

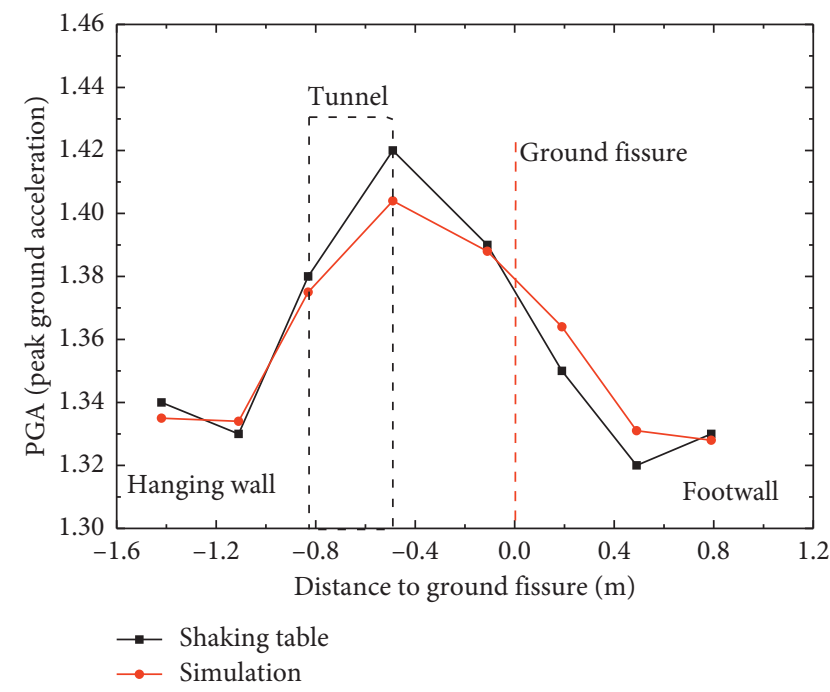

(b)

Figure 10: The PGA as a function of the distance to the fissure. (a) Surface of the fissure site. (b) Depth of $505 \mathrm{~mm}$. 


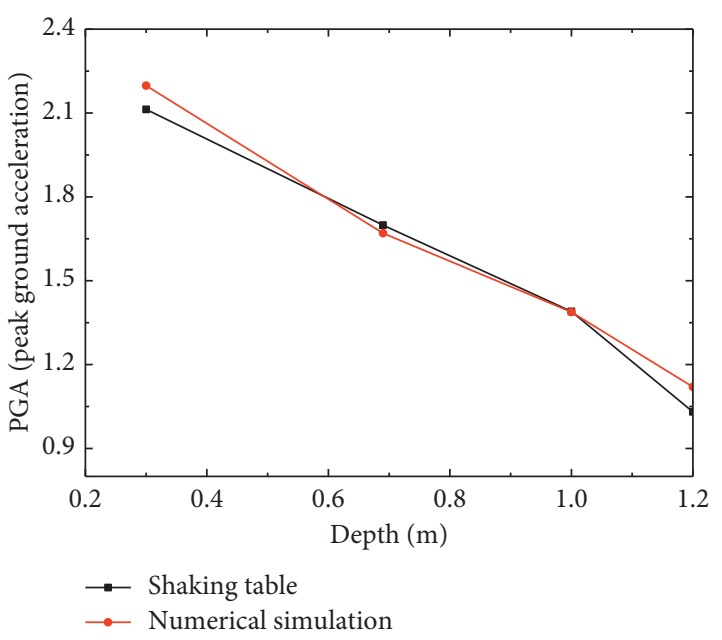

(a)

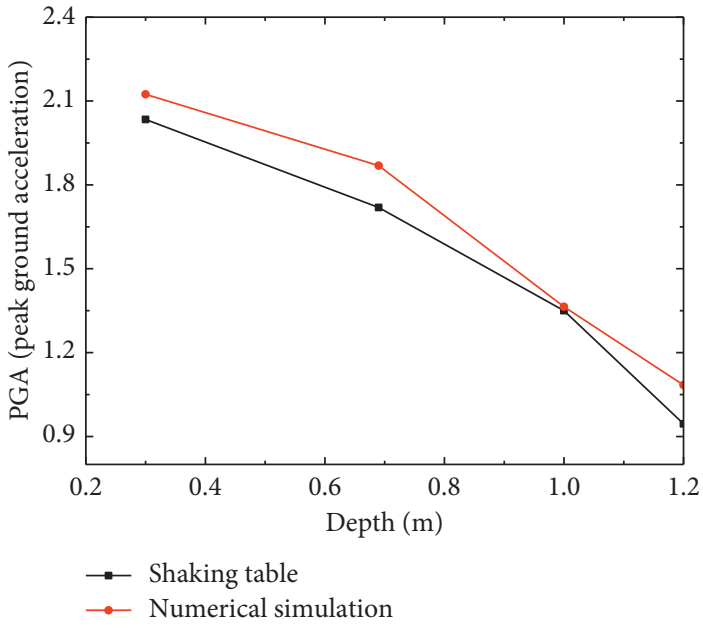

(b)

Figure 11: The relationship between the PGA and depth. (a) Hanging wall. (b) Footwall.

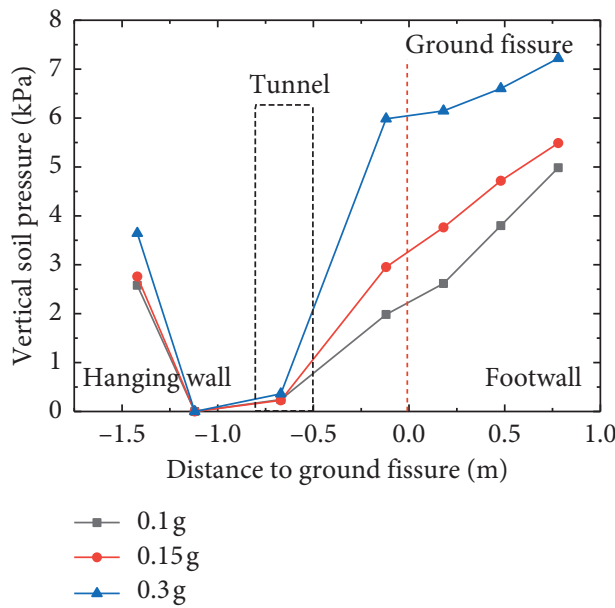

(a)

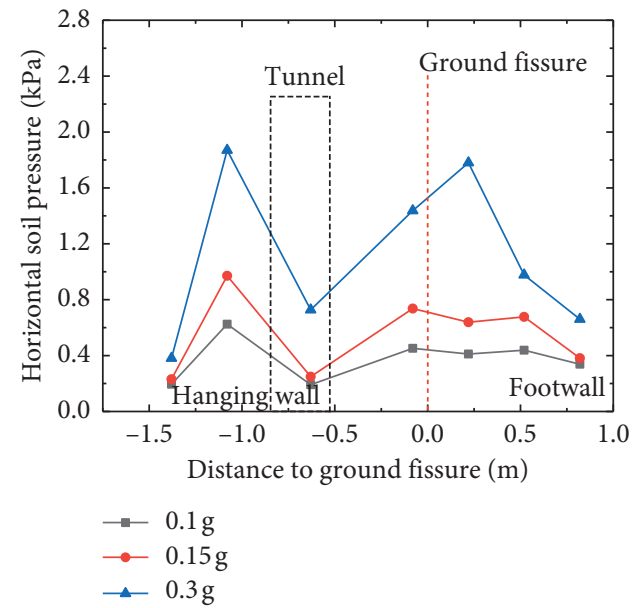

(b)

Figure 12: Changes in the soil pressure as a function of the distance from the ground fissure. (a) Vertical soil pressure. (b) Horizontal soil pressure.

Figure 12(b) shows the increments in the horizontal soil pressure for the synthetic Xi'an earthquake wave at different peak accelerations. The soil pressure sensors S2-1 to S2-7 were located at a burial depth above the tunnel. The horizontal soil pressure increments above the tunnel were less than the pressure increments elsewhere due to the influence that the tunnel had on the earthquake wave. The horizontal soil pressure had larger values both to the left of the tunnel and near the fissure in the hanging wall. The horizontal soil pressure increments decreased sharply near the tunnel; the earthquake energy loss in the tunnel structure may be responsible for this effect.

\section{Conclusions}

(1) The $f_{7}$ ground fissure was analyzed by monitoring the data from past decades. The displacement has a close relationship with water pumping and earthquakes. The vertical displacement is more dominant than twist and stretch displacements.

(2) The ground fissure site is characterized by a hanging wall effect. The acceleration amplification of the hanging wall was larger than that of the footwall at the surface and at a burial depth of $505 \mathrm{~mm}$. The width of the influenced zone was $30.0 \mathrm{~m}$ in the hanging wall and $15.0 \mathrm{~m}$ in the footwall.

(3) The magnification factor of the acceleration increased with the burial depth and peak acceleration of the earthquake waves.

(4) The PGA coefficient illustrated that the influenced area was 14 and $12 \mathrm{~m}$ in hanging wall and footwall, respectively.

(5) The vertical soil pressure was influenced by the tunnel and fissure during the earthquake. This 
pressure was larger in the hanging wall, particularly in areas near the fissure. The horizontal soil pressure above the tunnel was less than that in the surrounding area.

\section{Data Availability}

The data in the manuscript were obtained directly from the tests and software, such that the data in the manuscript are direct and reliable.

\section{Conflicts of Interest}

The authors declare that they have no conflicts of interest.

\section{Acknowledgments}

This research was supported by the National Natural Science Foundation of China (41502277, 41630634, and 41877250), the Fund of Key Laboratory of Mine Geological Hazards Mechanism and Control (2017KF06), the Special Fund for Basic Scientific Research of Central Colleges, Chang'an University (300102269504), the Fund of China Geological Survey (DD20160264), the National Basic Research Program of China (973 Program: 2014CB744700), and Natural Science Innovation Foundation of Department of Education of Guangdong Province (2016KTSCX001). All supports are gratefully acknowledged.

\section{References}

[1] T. L. Holzer and E. H. Pampeyan, "Earth fissures and localized differential subsidence," Water Resources Research, vol. 17, no. 1, pp. 223-227, 1981.

[2] J. Pacheco, J. Arzate, E. Rojas, M. Arroyo, V. Yutsis, and G. Ochoa, "Delimitation of ground failure zones due to land subsidence using gravity data and finite element modeling in the Queretaro valley," Engineering Geology, vol. 84, no. 3-4, pp. 143-160, 2006.

[3] N. D. Dobrev and B. Kost'ak, "Monitoring tectonic movements in the Simitli Graben, SW Bulgaria," Engineering Geology, vol. 57, no. 3-4, pp. 179-192, 2000.

[4] I. Sarkar, "The role of the 1999 Chamoli earthquake in the formation of ground cracks," Journal of Asian Earth Sciences, vol. 22, no. 5, pp. 529-538, 2004.

[5] N. Mohseni, A. Sepehr, S. R. Hosseinzadeh, M. R. Golzarian, and F. Shabani, "Variations in spatial patterns of soil-vegetation properties over subsidence-related ground fissures at an arid ecotone in northeastern Iran," Environmental Earth Sciences, vol. 76, no. 6, p. 234, 2017.

[6] M. Hori and N. Vaikunthan, "Analysis of smooth crack growth in brittle materials," Mechanics of Materials, vol. 28, no. 1-4, pp. 33-52, 1998.

[7] J.-B. Peng, L.-W. Chen, Q.-B. Huang, Y.-M. Men, W. Fan, and J.-K. Yan, "Physical simulation of ground fissures triggered by underground fault activity," Engineering Geology, vol. 155, pp. 19-30, 2013.

[8] Z. P. Sheng, D. C. Helm, and J. Li, "Mechanisms of earth fissurin gcaused by groundwater withdrawal," Environmental and Engineering Geoscience, vol. 9, no. 4, pp. 313-332, 2003.
[9] K. W. F. Howard and W. F. Zhou, "Overview of ground fissure research in China," Environmental Earth Science, vol. 78, no. 3, pp. 78-97, 2019.

[10] J. B. Peng, J. W. Qiao, Y. Q. Leng, F. Y. Wang, and S. Z. Xue, "Distribution and mechanism of the ground fissures in Wei River Basin, the origin of the Silk road," Environmental Earth Sciences, vol. 75, no. 8, p. 718, 2016.

[11] N. Liu, Q. Huang, Y. Ma et al., "Experimental study of a segmented metro tunnel in a ground fissure area," Soil $D y$ namics and Earthquake Engineering, vol. 100, pp. 410-416, 2017.

[12] N. Liu, X. Feng, Q. Huang et al., "Dynamic characteristics of a ground fissure site," Engineering Geology, vol. 248, pp. 220229, 2019.

[13] D. Pitilakis, M. Dietz, D. M. Wood, D. Clouteau, and A. Modaressi, "Numerical simulation of dynamic soil-structure interaction in shaking table testing," Soil Dynamics and Earthquake Engineering, vol. 28, no. 6, pp. 453-467, 2008.

[14] H. Chen, X. Li, W. Yan, S. Chen, and X. Zhang, "Shaking table test of immersed tunnel considering the geological condition," Engineering Geology, vol. 227, pp. 93-107, 2017.

[15] W.-C. Cheng, J. C. Ni, J. S.-L. Shen, and H.-W. Huang, "Investigation into factors affecting jacking force: a case study," Proceedings of the Institution of Civil Engineers-Geotechnical Engineering, vol. 170, no. 4, pp. 322-334, 2017.

[16] W.-C. Cheng, Z.-P. Song, W. Tian, and Z.-F. Wang, "Shield tunnel uplift and deformation characterisation: a case study from Zhengzhou metro," Tunnelling and Underground Space Technology, vol. 79, pp. 83-95, 2018.

[17] W.-C. Cheng, J. C. Ni, A. Arulrajah, and H.-W. Huang, "A simple approach for characterising tunnel bore conditions based upon pipe-jacking data," Tunnelling and Underground Space Technology, vol. 71, pp. 494-504, 2018. 


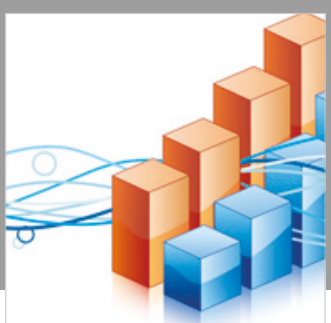

Advances in

Operations Research

\section{-n-m}
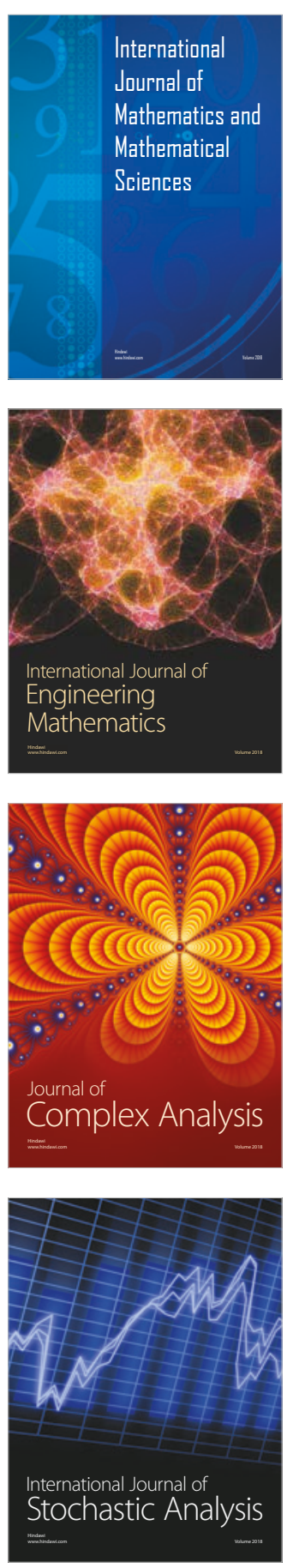
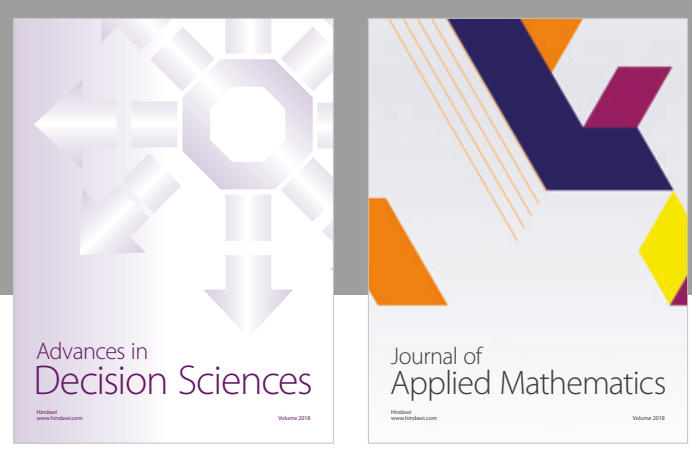

Journal of

Applied Mathematics
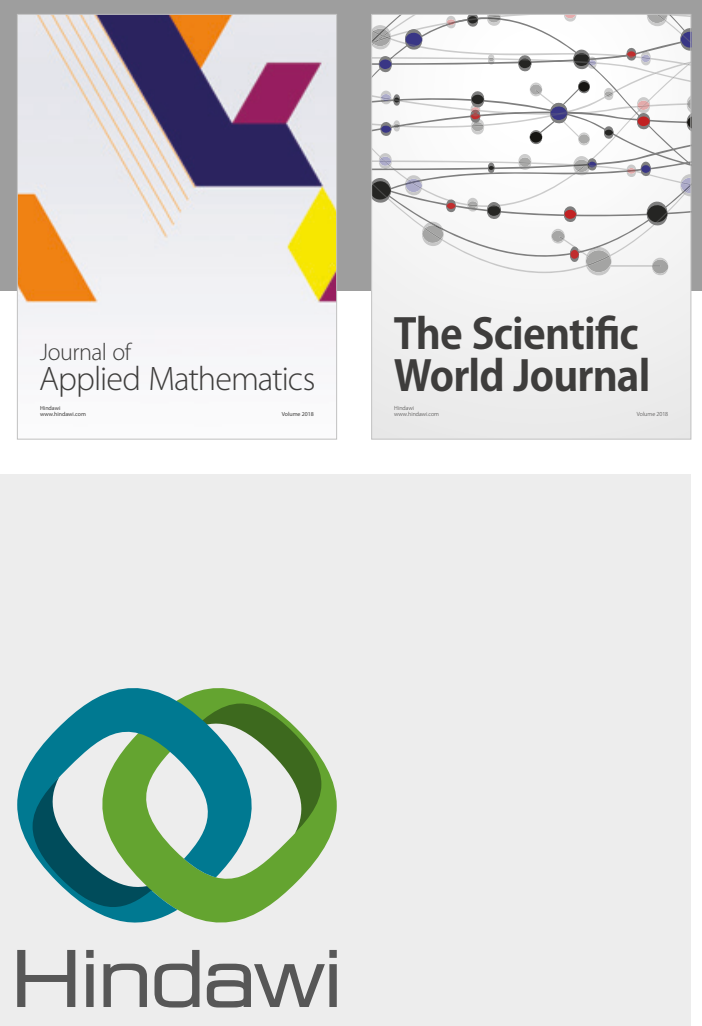

Submit your manuscripts at

www.hindawi.com

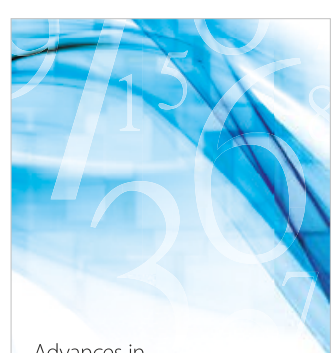

Advances in
Numerical Analysis
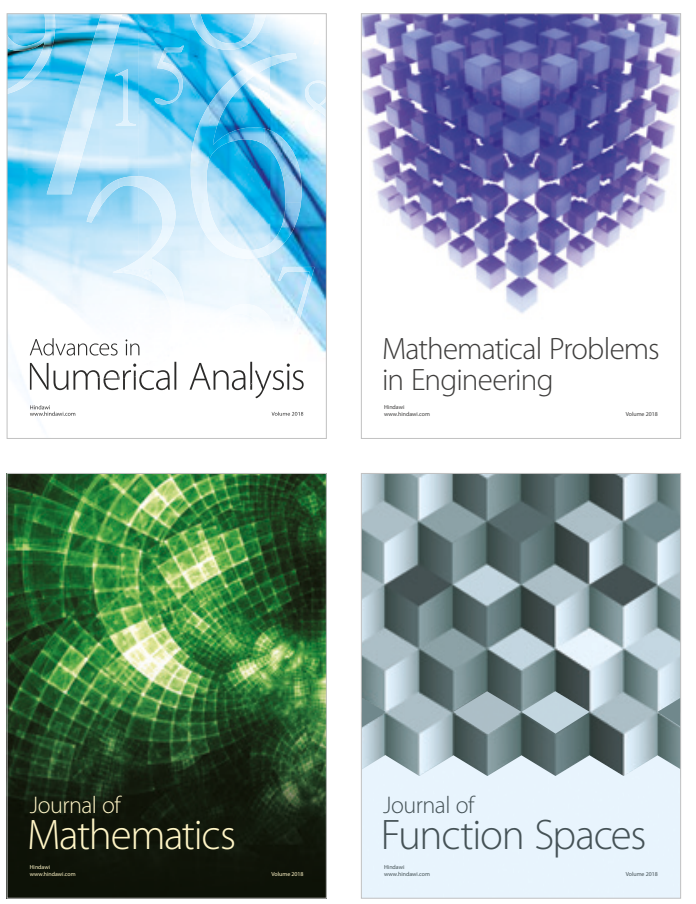

Mathematical Problems in Engineering

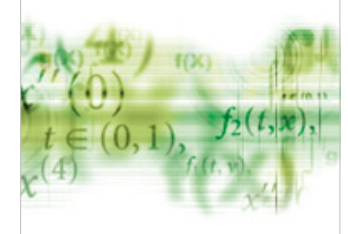

International Journal of

Differential Equations

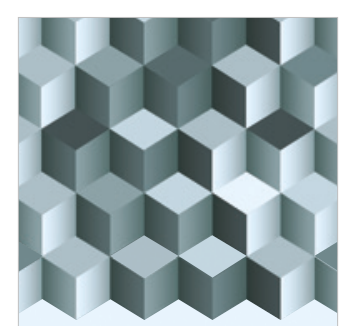

Journal of

Function Spaces
The Scientific

World Journal

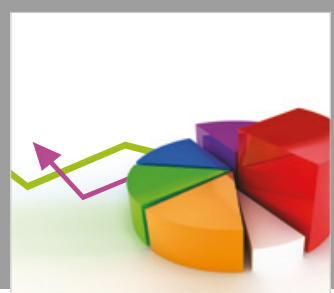

Journal of

Probability and Statistics
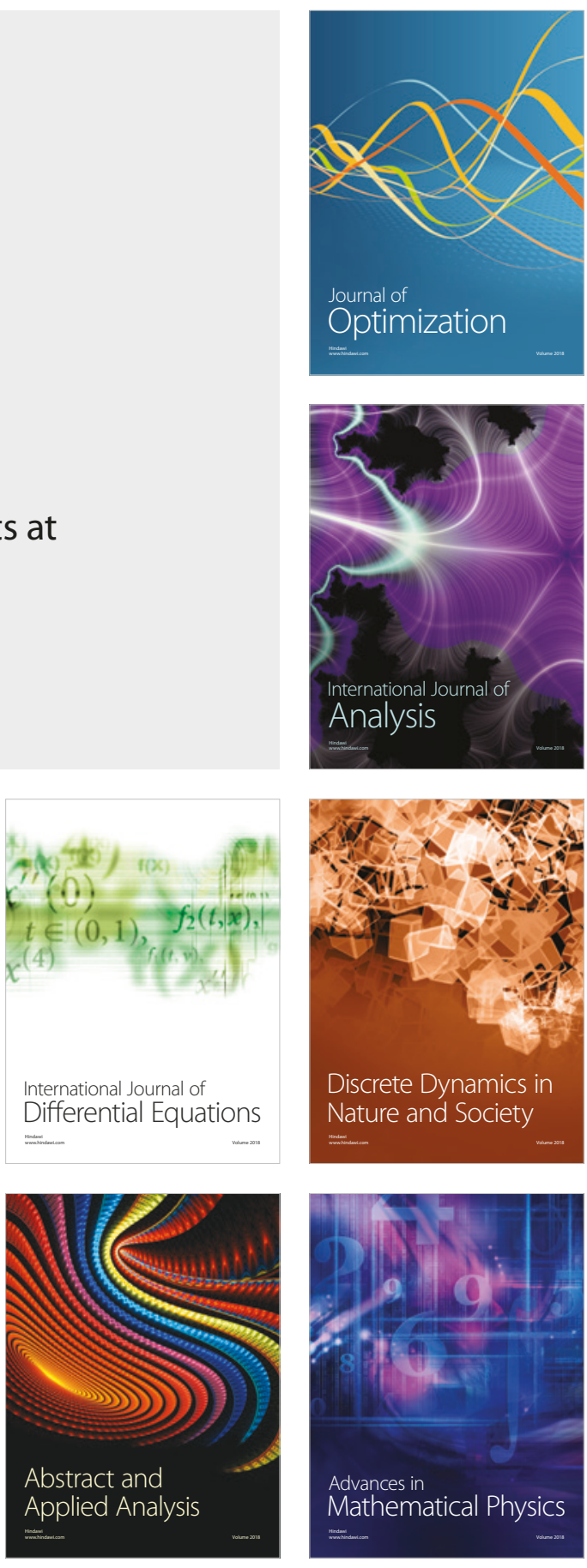